Portland State University

PDXScholar

1-30-1985

\title{
A Comparison of Preschool Scores on the PPVT-R and the TELD
}

Diana Schneider

Portland State University

Follow this and additional works at: https://pdxscholar.library.pdx.edu/open_access_etds

Part of the Speech Pathology and Audiology Commons Let us know how access to this document benefits you.

Recommended Citation

Schneider, Diana, "A Comparison of Preschool Scores on the PPVT-R and the TELD" (1985). Dissertations and Theses. Paper 3527.

https://doi.org/10.15760/etd.5411

This Thesis is brought to you for free and open access. It has been accepted for inclusion in Dissertations and Theses by an authorized administrator of PDXScholar. Please contact us if we can make this document more accessible: pdxscholar@pdx.edu. 
AN ABSTRACT OF THE THESIS OF Diana Schneider for the Master of Sctence in Speech Communication with an emphasis in Speech-Language Pathology presented January 30, 1985 .

Title: A Comparison of Preschool Scores on the PPVT-R and the TELD. APPROVED BY MEMBERS OF THE THESIS COMMITTEE :

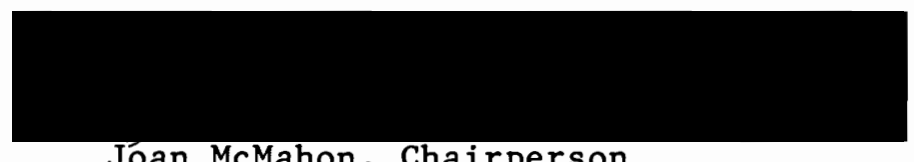

Joan McMahon, Chairperson
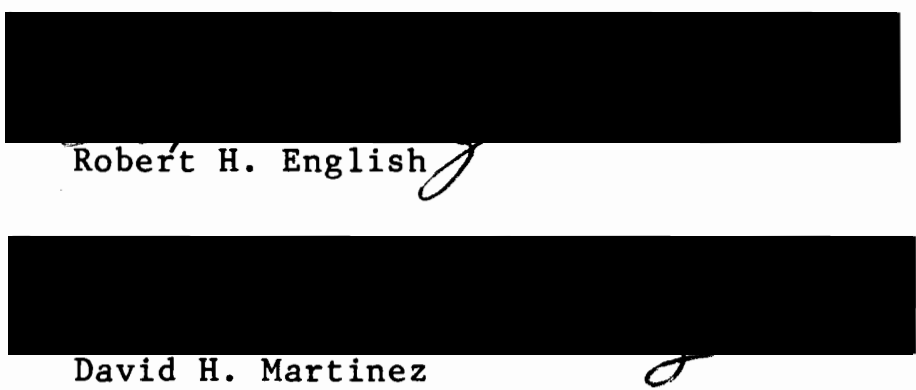

The Peabody Picture Vocabulary Test - Revised - PPVT-R (Dunn and Dunn, 1981) is a test of hearing vocabulary which was published in 1981. It was suggested by Dunn and Dunn that the test should be useful "as an initial screening device in scanning for bright, low ability, and language impaired children who may need special attention." Since accuracy in screening is desired, information regarding the strength of the correlation between the PPVT-R and age equivalents from a comprehensive language measure was needed. 
The purpose of this study was to compare PPVT-R age equivalents with language ages from the Test of Early Language Development - TELD (Hresko, Reid, and Hammi11, 1981) for a preschool population. This study sought to find the strength of association between the PPVT-R age equivalents and the TELD language ages. The subjects used in the study were 54 preschool children ranging in age from 3-6 through 4-7 years. Normal children were selected for the study based on their chronological age, sex, and socioeconomic status - SES.

Results indicated a significant and high correlation between the PPVT-R and TELD age equivalents and language ages, standard scores and language quotients, and also between percentiles. Results also showed that the mean TELD language age was consistently higher than the mean PPVT-R age equivalent for the overall sample and for each age, sex, and SES group.

The mean PPVT-R age equivalents were consistently closer than the TELD mean language ages to chronological age. The PPVT-R appeared to be slightly more valid in measuring overall language performance (as defined by the TELD) with females than with males. When results from this study were compared with the results from a similar study (McLoughlin and Gullo, 1984), the correlation coefficient from the present study was found to be higher than the coefficient from the McLoughlin and Gullo study when standard scores and language quotients from the TELD and PPVT-R were correlated. (McLoughlin and Gullo study $-.627, \mathrm{p}<.001$; present study $-.708, \mathrm{p}<.001)$. 
A COMPARISON OF PRESCHOOL SCORES

ON THE PPVT-R AND THE TELD

by

DIANA SCHNEIDER

A thesis submitted in partial fulfillment

of the requirement for the degree of

MASTER OF SCIENCE

in

SPEECH COMMUNICATION

with an emphasis in

SPEECH-LANGUAGE PATHOLOGY

Portland State University

1985 


\section{TO THE OFFICE OF GRADUATE STUDIES AND RESEARCH;}

The members of the Committee approve the thesis of Diana Schneider presented January 30, 1985 .

Jóan McMahon, Chairperson

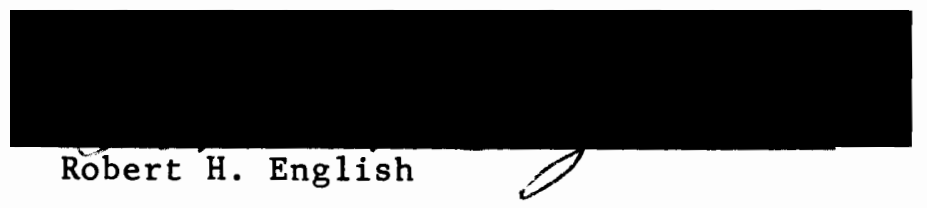

David H. Martinez

APPROVED :

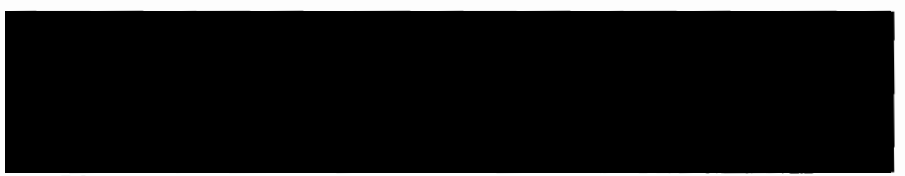

Theodore G. Grove, Chair, Department of Speech Communication

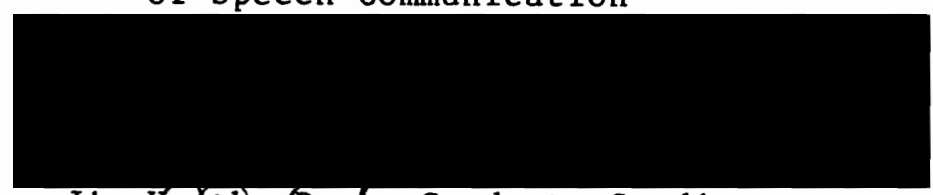

Jim Heath, Deah, Graduate Studies

and Research 


\section{ACKNOWLEDGEMENTS}

I am deeply grateful for my parents' encouragement and support which enabled me to achieve my educational goals.

I extend my sincere thanks to Joan McMahon, M.S. and Robert English, D. Ed. for their hours of assistance in the design and writing of this thesis; to Theodore Grove, Ph.D. and Becky Bragg for their guidance with statistics; and to David Martinez, Ph.D. for his helpful suggestions during the oral examination.

I wish to thank the preschool directors who allowed me to disrupt their classrooms for testing purposes.

A special thanks is extended to Marilyn Caum for editing, typing, and timely deadline reminders; and to my fellow graduate students for their continuous encouragement.

Finally, I am grateful for the emotional support given me by Rob during the past four years. 
TABLE OF CONTENTS

PAGE

ACKNOWLEDGEMENTS . . . . . . . . . . . . . . . . . . .

LIST OF TABLES . . . . . . . . . . . . . . . . . . . . . vi vi

CHAPTER

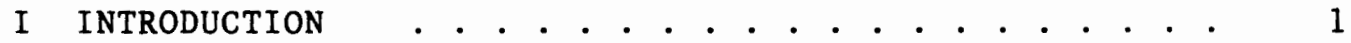

Statement of Purpose . . . . . . . . . . . . 3

I I REVIEW OF THE LITERATURE . . . . . . . . . . . . . . 4

Peabody Picture Vocabulary Test . . . . . . . . . 4

Peabody Picture Vocabulary Test - Revised . . . . 8

Test of Early Language Development . . . . . . . 12

Summary of the Review . . . . . . . . . . . 14

II METHODS . . . . . . . . . . . . . . . . . 15

Subjects . . . . . . . . . . . . . . . 15

Instrumentation . . . . . . . . . . . 15

Procedures . . . . . . . . . . . . . . 16

IV RESULTS AND DISCUSSION . . . . . . . . . . . . . . . 19

Correlations Between PPVT-R Age Equivalents
and TELD Language Ages
. . . . . . . . . . . 19

Correlations Between PPVT-R Standard Scores
and TELD Language Quotients . . . . . . . . 22

Correlations Between PPVT-R and TELD Percentiles • 22

Correlations Between Chronological Age, PPVT-R
Age Equivalents, and TELD Language Ages . . . . 25

Discussion . . . . . . . . . . . . . . . 28 


\section{LIST OF TABLES}

I Mean Age Equivalents and Language Ages, PPVT-R/TELD

Correlation Coefficients, $t-T e s t$ Values, and

Significance Levels According to Subject

Grouping . . . . . . . . . . . . . . . . . .

II Mean Standard Scores and Language Quotients, PPVT-R/TELD

Correlation Coefficients, $t$-Test Values, and

Significance Levels According to Subject

Grouping . . . . . . . . . . . . . . . . . .

II Mean Percentiles, PPVT-R/TELD Correlation Coefficients, t-Test Values, and Significance Levels According

to Subject Grouping . . . . . . . . . . . .

IV Correlation Coefficients, t-Test Values, and Significance Levels which Resulted from PPVT-R/Chronological Age and TELD/Chronological Age Comparisons

$\mathrm{V}$ Number of Months by which Mean TELD Language Ages are Greater than Mean PPVT-R Age Equivalents by Subject Grouping . . . . . . . . . . . . . . . 
V SUMMARY AND IMPLICATIONS . • . . . . . . . . . . . . 37

Summary •. . . . . . . . . . . . . . . . 37

Implications . . . . . . . . . . . . . 38

BIBLIOGRAPHY . . . . . . . . . . . . . . . . . . . . . 40

APPENDICES . . . . . . . . . . . . . . . . . . . . . . . 43 


\section{CHAPTER I}

\section{INTRODUCTION}

Speech-Language Pathologists utilize many different language tests to identify preschool children who need more extensive language evaluations. In order to interpret these tests accurately, information pertaining to the validity and meaning of scores attained on the tests is needed.

One of the most popular language tests, the Peabody Picture Vocabulary Test - PPVT (Dunn, 1959), is a receptive vocabulary test with norms for children from 2-6 through 18-0 years of age. Receptive vocabulary mental ages, intelligence quotients (IQ) scores, and percentiles may be derived from PPVT raw scores. The PPVT has been correlated with receptive vocabulary tests, such as: The Vocabulary Subtest of the Stanford-Binet Intelligence Test (Terman and Merril1, 1960) and the Ful1 Range Picture Vocabulary Test (Ammons and Ammons, 1948). The mean correlation coefficient was .72 when the PPVT was compared with tests of receptive vocabulary; however, a correlation of .32 was obtained when the PPVT was correlated with the Auditory Reception and Verbal Expression subtests of the Illinois Test of Psycholinguistic Abilities (Kirk, McCarthy, and Kirk, 1968). This low correlation suggested that the PPVT may not be a good indicator of language age when used as a quick screening measure.

The PPVT has been revised and is known as the Peabody Picture Vocabulary Test-Revised - PPVT-R (Dunn and Dunn, 1981). The PPVT-R has 
norms for ages 2-6 through 40-0. This test also gives age equivalent values for receptive vocabulary as well as percentiles, standard scores, and stanines. Dunn and Dunn (1981) have suggested that the PPVT-R should be useful "as an initial screening device in screening for bright, low ability, and language impaired children who may need special attention." They postulated that a test of hearing vocabulary is able to discriminate between groups of normal and language impaired children. To make this suggestion, it would seem that studies correlating the PPVT-R with comprehensive language tests, which include expressive and receptive items, need to be undertaken and reported. Naglieri (1981) has compared the PPVT-R with the McCarthy Scales of Children's Abilities - MSCA (McCarthy, 1972). The items on the MSCA include verbal skills, number concepts, motor coordination, and other cognitive and motor skills. He found that the PPVT-R correlated highly with the MSCA when the subtests of the MSCA contained a verbal component. Naglieri (1981) warned that the PPVT-R should not be used as a substitute for the MSCA, and, additionally, he has noted that the PPVT-R may be more appropriate as a brief measure of verbal comprehension.

Breen (1981) and Prasse and Bracken (1981) compared standard scores from the Wechsler Intelligence Scale for Children-Revised WISC-R (Wechsler, 1974) with standard scores of the PPVT-R and found that the PPVT-R underestimates the intellectual abilities of preschool children. They concluded that the PPVT-R should not be used as an intelligence measure.

Since Dunn and Dunn (1981) suggested that the PPVT-R be used as a screening test of language ability, it seems critical to compare the 
age equivalents from a comprehensive (expressive and receptive) screening measure such as the Test of early Language Development - TELD (Hresko, Reid, and Hammi11, 1981).

According to Hresko, Reid, and Hammill (1981) an assessment of language must be comprehensive in order to sample all the behaviors thought related to language ability. The TELD was developed to provide a device that could be used to quickly identify children between the ages of 2-0 and 7-11 years who are in need of more extensive language evaluations. Other intentions of the test are to provide a means of documenting children's progress, and to suggest instructional practices. Even though the measure is quick (approximately fifteen-twenty minutes), it includes items which measure language skills in the modes of expressive and receptive language in the dimensions of content (semantics) and form (phonology, syntax, and morphology).

The review of the literature reveals a need to compare the PPVT-R with tests which measure overall language abilities of children. Hence, the present investigation was designed to help meet this apparent need.

\section{Statement of Purpose}

The purpose of this investigation was to compare the test performances of normal preschool children on the PPVT-R to their performances on the TELD.

The specific question to be answered by this investigation was:

What is the significance of the correlation between the age equivalent values of the PPVT-R and the language ages of the TELD? 
CHAPTER II

\section{REVIEW OF THE LITERATURE}

Speech-Language Pathologists are interested in identifying children who have speech/language delays or disorders so that more extensive evaluations can be performed. Identification is usually accomplished through speech/language screening (a brief measure, approximately fifteen minutes in length, which identifies children with mild as well as severe speech and/or language problems). Accuracy in screening requires that instruments not yield a high number of false negative or false positive scores. False positives occur when test scores suggest a delay or disorder when language skills are actually within normal limits. False negatives occur when test scores suggest language and speech development is within normal limits when it is actually delayed or disordered. False negatives and false positives are minimized when the measure has been shown, through research, to be reliable and valid for the population with whom the test is used (Joiner, 1978).

\section{Peabody Picture Vocabulary Test}

One of the tests that has been popular in screening preschool children is the Peabody Picture Vocabulary Test - PPVT (Dunn, 1959). The PPVT is a test of receptive vocabulary in which children point to pictures which correspond with words verbally presented by the examiner. The test consists of two equivalent forms ( $A$ and $B$ ) with norms for children from 2-6 through 18-0 years of age. A mental age, intelligence 
quotient (IQ) and percentile score can be derived from the raw score.

$\underline{\text { PPVT as an Intelligence Measure }}$

The results from the PPVT have been correlated with intelligence, achievement, and language measures. As a result of these studies researchers have cautioned against the use of the PPVT as an intelligence measure (Piers, 1965; DiLorenzo and Brady, 1968; Ritter, Duffey, and Fischman, 1974; Covin, 1977; Darley and Spriesterbach, 1978; and Emerick and Hatten, 1979). DiLorenzo and Brady (1968) found four specific weaknesses of the PPVT when used as an IQ test with preschool children. They compared the scores of 563 children between the ages of 3-6 and 4-6 years on the PPVT and the Revised Stanford-Binet - RSB (Terman and Merril1, 1960). The RSB is an intelligence test in which the items primarily require comprehension of verbal instructions and production of verbal responses. Only 20 percent of the items are performance tasks. The correlations which resulted from the comparison were high (Form A and RSB .78 and Form B and RSB .79); however, the absolute difference between the means of the two tests was also quite high which suggests that neither test should be used as a substitute for the other. The mean RSB IQ score was 93.68 and the PPVT mean IQ was 84.85 . The mean difference between IQ points was 8.83 which was a significant difference. In addition to the PPVT's underestimations of IQ scores, the following limitations were suggested by DiLorenzo and Brady (1968): 1) the use of large, six month intervals in the standardization tables; 2) lack of comparable growth between age level norms; 3) lack of comparability of changes on either side of the mean; and 4) large discrepancies between PPVT IQ scores and IQ scores of other established 
intelligence tests.

Weak Correlations Between the PPVT and Comprehensive Language Measures

Studies show that low to moderate correlations have resulted when the PPVT scores were correlated with scores of comprehensive language measures (expressive and receptive). Carr, Brown, and Rice (1967) administered both forms of the PPVT to 90 EMR children and compared the PPVT scores with scores on the Illinois Test of Psycholinguistic Abilities - ITPA (Kirk, McCarthy, and Kirk, 1968). The purpose of the ITPA is to measure psycholinguistic abilities. Correlation coefficients between mental ages on Form $A$ of the PPVT and raw scores of the ITPA ranged from .18 to .47 and between Form $B$ and the ITPA the correlations ranged from .22 to.58. From these data, Carr, Brown, and Rice (1967) concluded that the PPVT should be used solely to measure "hearing vocabulary," and they questioned the PPVT's validity as a test of psycholinquistic ability as defined by the ITPA.

Taylor (1975) also commpared Form A of the PPVT with ITPA scores. He found that the scores (type of scores were not reported) from the two tests did not correlate significantly when 133 lower ses kindergarten and first grade children were tested. The correlations between the PPVT and ITPA subtests ranged from .17 to .57 . The correlation between the PPVT and the ITPA total score was..33. This correlation was compatible with the correlations derived in the Carr, Brown, and Rice (1967) study. Taylor (1975) concluded that the PPVT does not provide a good measure of overall language abilities, but that it did correlate more highly with specific subtests of the ITPA than with the ITPA total score. 
Cartwright and Lass (1974) administered the Token Test - TT (DeRenzi and Vignolo, 1968), the Northwestern Syntax Screening Test NSST (Lee, 1971) and the PPVT to 30 children ranging in age from 5-0 to 7-11 years. The TT is an auditory comprehension test in which items increase in length and complexity. The NSST is a receptive and expressive language measure. The correlation between the TT and NSST was .63 which indicated a moderately high correlation. The coefficients that resulted from a comparison of the TT with the PPVT (form not indicated) and the NSST with the PPVT were both .06 which indicates a low correlation and suggests that the tests are measuring different abilities. The NSST data included both expressive and receptive forms.

Moderate Correlations Between the PPVT and Comprehensive Measures Sommers, Erdige, and Peterson (1978) administered the Test for Auditory Commprehension of Language - TACL (Carrow, 1973), the NSST (Lee, 1971) and the PPVT (form not reported) to 122 minimally brain damaged children. The TACL is a language comprehension test which requires a non-verbal response. The correlation between the TACL and PPVT was high (.74). The comparison between the receptive portion of the NSST and the PPVT was also high (.70) and the comparison between the expressive portion of the NSST and the PPVT was moderate (.52). These findings are in disagreement with the findings of Carwright and Lass (1974) in which the correlation between the NSST total score and the PPVT was very low $(.06)$.

Taylor (1979) administered the McCarthy Scales of Children's abilities - MSCA (McCarthy, 1972) and the PPVT to 41 kindergarten 
children. The MSCA is a developmental test which consists of six scales; Verbal (expressive and receptive), General Cognitive, Memory, Perceptual-Performance, Quantitative, and Motor. Taylor found that the PPVT correlated significantly with the MSCA Verbal Scale (.52), the Memory Scale (.35) and with the General Cognitive Index (.47). Based on the correlations obtained in this study, however, Taylor concluded that the two tests are not similar enough to warrant their interchangeable use in making educational decisions.

The above research would appear to suggest that the PPVT correlated moderately to highly with other tests of receptive language. It also suggests that correlations between the PPVT and comprehensive language measures have been in the low to moderate range.

\section{Peabody Picture Vocabulary Test - Revised}

The PPVT has been revised and is known as the Peadbody Picture Vocabulary Test - Revised - PPVT-R (Dunn and Dunn, 1981). The norms were changed to include nation-wide standardization; norms data were provided in finer increments; adult norms were added; "mental age" and "intelligence quotient" were replaced by "age equivalent" and "standard score"; drawings were reworked to provide a better racial and sex balance; twenty-five items were added to each form; items were spaced to make the test equally sensitive across the whole test; two-thirds of the stimulus items were replaced with new items; and a new set of test items was developed so that each form would have a corresponding set of stimulus pictures.

Research concerning the PPVT-R includes equivalency, reliability, and validity studies. In an equivalency study by Choong and McMahon 
(1983), Forms A and B of the PPVT were compared with Forms $L$ and $M$ of the PPVT-R. Eighty children ranging in age from 3-6 to 4-6 years were tested and it was found that the PPVT mental ages were consistently higher than the age equivalents of the PPVT-R. The mean PPVT mental age was nine months higher than the mean PPVT-R age equivalent. They also found that the PPVT-R mean age equivalents were significantly closer than those from the PPVT to the mean chronological ages of the children tested. Additionally, it was determined that Form L age equivalents were generally lower than Form $M$ age equivalents. In summary, they found that the PPVT-R was more accurate than the PPVT in determining receptive vocabulary age equivalents in preschool children. Naglieri and Naglieri (1981) compared performances of 88 children, ranging in age from 2-6 to 5-11 years, on the PPVT-R and the PPVT. They found that the PPVT scores were significantly higher than the PPVT-R scores.

Pedriana and Bracken (1982) administered both forms of the PPVT and PPVT-R to 31 gifted children between the ages of 9-0 and 12-0 years. Their results also show the PPVT IQ scores to be consistently higher than the standard scores of the PPVT-R.

In an alternate form equivalency study, by McCallum and Bracken (1981), Forms $L$ and $M$ were administered to 72 White and Black preschool children between the ages of 2-7 and 6-9 years. Results indicated that the Form $M$ mean raw scores were significantly higher than the Form $L$ raw scores for Black children. The Form M standard score mean also was significantly higher than the Form L standard score mean. Form L appeared to be more difficult for Black children. They also found that 
there were no significant diferences between the forms for White children when standard scores were compared. When raw scores were compared for the total group, significantly higher scores were obtained on Form M. This research is consistent with Choong and McMahon's (1983) findings that Form $L$ age equivalents were generally lower than Form M age equivalents.

Stoner (1981) administered both forms of the PPVT-R to 79 headstart children between the ages of 3-9 and 6-3 years. She found that scores on Form $M$ were significantly higher than scores on Form L, however, the correlation between the forms was .79 which supports the equivalency of the two forms for preschool children.

There are three studies, to date, regarding the concurrent validity of the PPVT-R. In a study by Naglieri (1981), PPVT-R standard scores were compared with the McCarthy Scales of Children's AbilitiesMSCA (McCarthy, 1972) scores and the Peabody Individual Achievement Test - PIAT (Dunn and Markqwardt, 1970) scores. His subjects were 26 children from kindergarten, first, second, and third grades. Results of the study revealed that the PPVT-R was positively and significantly correlated with the subtests of the PIAT. The correlations ranged from . 32 to .61 with a total test correlation of .53 . The mean PPVT-R and PIAT total scores, however, were significantly different $(104.5$ and 114.6 respectively). The PPVT-R correlated highly with the MSCA when subtests contained a verbal component (Verbal .79, Quantitative .75, General Cognitive .78, and Memory .72). The PPVT-R did not correlate as highly with MSCA subtests which were less verbal (Perceptual-Performance .27, and Motor .23). These correlations were much higher 
than those between the PPVT and MSCA in Taylor's (1979) study (Verbal .53, Memory .35, and General Cognitive .47).

Prasse and Bracken (1981) compared the performances of 67 Black, Hispanic, and White EMR students on the PPVT-R and the Wechsler Intelligence Scale for Children-Revised - WISC-R (Wechsler, 1974). The children ranged in age from 7-3 to 15-8 years. They found the correlations to be 1ow. Subtest correlations ranged from .04 (Digit Span) to.33 (Picture Completion). The Verbal Scale correlation was .11. These data support the elimination of IQ scores from those derived from the PPVT-R raw scores. These scores reflected the same low correlations as the correlation between the PPVT and the Revised Stanford Binet - RSB (Terman and Merri11, 1960).

Breen (1981) administered the PPVT-R and the WISC-R to 32 students, ranging in age from 6-0 to 15-0 years, who were referred for learning disabilitites or emotional disturbances. Significant differences, which suggest that the PPVT-R is not a reliable IQ measure, were noted between the mean PPVT-R standard scores and each of the three WISC-R intelligence quotients. The PPVT-R standard scores were lower than WISC-R scores by an average of ten points in each IQ scale. The correlations between the PPVT-R scores and the Verbal IQ and Full Scale quotients, however, were high.

Gullo and McLoughlin (1982) compared 30 non-referred, White, middle class 3-0 and 4-0 year old preschool children's PPVT-R standard scores with the General Cognitive Index and Subtest scores of the MSCA. Results indicated a correlation of $.59(\mathrm{p}<.001)$ for the total group. Correlations of $.58(p<.001)$ with the Verbal Subtest, .62 $(p<.001)$ with 
the Perceptual Subtest, .38 ( $p<.05)$ with the Quantitative Subtest, and $.35(p<.05)$ with the Motor Subtest were also reported. These researchers also found that the PPVT-R standard scores significantly underestimated scores of the 3-0 year olds on the MSCA. The PPVT-R standard scores were judged equivalent to the MSCA General Cognitive Index for 4-0 year olds. These correlations are weaker than those in Naglieri's (1981) study.

The above review of the literature has presented results of equivalency, reliability, and concurrent validity studies which have compared the PPVT-R to general cognitive and intelligence measures. The earlier PPVT research tends to indicate that the PPVT was not an adequate overall language screening instrument. Its revision has been shown to produce age equivalents which are closer to chronological age than age equivalents of the PPVT. The revision also has been shown to correlate more highly than the PPVT with verbal portions of general cognitive and developmental measures. Since Dunn and Dunn (1981) have suggested the PPVT-R should be useful as an indicator of children's overall language ability, it is necessary to find out how strongly the age equivalents of the PPVT-R correlate with the age equivalents of a comprehensive language screening test such as the Test of Early Language Development - TELD (Hresko, Reid, and Hammill, $1981)$

\section{Test of Early Language Development}

Even though the TELD is new and has not been researched extensively, the standardization sample appears to be fairly representative 
of the nation as a whole and reliability and validity have been shown to be acceptable. The standardization sample was selected to be similar to the United States population according to the Statistical Abstract of the United States (1979). The sample consisted of 1184 children from eleven states ranging in age from 3-0 to 7-0 years.

Reliability coefficients for content and time sampling round to .90 for all age groups. All of the coefficients of discrimination are significant $(p<.01)$. Items were found to be most acceptable at ages 4-0 through 6-0, but the test items also were shown to have discriminating value in identifying communicatively disordered 3-0 to 7-0 year olds. The coefficients of correlation for ages 3-0 and 7-0 were .52 and .51 respectively.

Criterion related validity was studied by comparing the TELD with more established tests sharing the same or similar purposes. The TELD was compared to the Preschool Language Scale - PLS (Zimmerman, Steiner, and Evatt, 1979). The PLS is a test of receptive and expressive language development. Three year olds were used for this comparison and the correlation was moderate (.46). The TELD also was compared with The Test of Language Development - TOLD (Newcomer and Hammill, 1979) using 5-0 and 6-0 year old subjects. The TOLD is a test of receptive and expressive language abilities. The study resulted in correlations of .66 and .80 respectively. Six year olds also were used when the TELD scores were compared to scores from reading and achievement tests and the correlations ranged form .58 to .75 respectively. The authors stated that these correlations are high enough to support the TELD's cirterion related validity. 
The TELD has been shown to have construct validity because the abilities measured have been shown to be developmental in nature and correlate significantly to chronological age (.80).

The TELD's ability to discriminate between normal and communicatively disordered children was measured by administering the TELD to 7 communicatively disordered children which were 3-6 years of age. The TELD language quotients for these children were more than one standard deviation below the mean which indicated a possible communication disorder and supported the probable discrimination ability of the TELD.

\section{Summary of the Review}

In summary, the PPVT generally correlated highly with established tests of receptive language, but did not correlate as highly with language tests which measure expressive as well as receptive language abilities. The PPVT-R has been shown to yield equivalent scores on Forms $L$ and $M$ for White children and significantly higher scores on Form $M$ for Black children. Studies also showed moderate to high correlations between PPVT-R and General Cognitive test scores.

In the manual of the PPVT-R, Dunn and Dunn (1981) have suggested that the PPVT-R may be used as a quick indicator of overall language ability. The above data is valuable in supporting this suggestion, but more research is needed with a sampling of preschool children to determine the validity of the PPVT-R as a language screening instrument. 
CHAPTER III

METHODS

\section{Subjects}

The subjects used in this study were 54 children ranging in age from 3-6 to 4-7 years with no known speech, language, hearing, or physical disabilities as reported by teachers. The upper, middle, and lower socioeconomic levels were represented in the sample. Preschool directors were requested to provide information as to the socioeconomic status of their students' families and this information was further verified by the method in the paragraph below. Parental permission was required for the inclusion of children in the study (see Appendix A).

\section{Instrumentation}

\section{Hearing Screen}

Model 1653 General Radio Sound Level Meter, Berlat Concert Tone Series 30 Mixer with VU Meter, and an Electrovoice RE Dynamic Cardoid Microphone (150 ohms) were used to calibrate the examiner's level of presentation of verbal stimuli in the clinic (see Appendix B for specifications).

\section{SES Status}

In order to assess the SES status of each of the preschool children's parents, the following information was solicited: 1) occupation 
and 2) years of education of the major wage earner in each of the preschool children's families. These data were then compared with data from the U.S. Census Working Paper Number 15 (1963). The mean SES level was calculated for each preschool. The information was classified into a percentile form denoting the SES status of each preschool. $\underline{\text { PPVT-R }}$

The PPVT- $R$ is a non-verbal test of hearing vocabulary which is normed for ages 2-6 through 40-0. It is composed of 175 stimulus plates for each of the alternate forms ( $L$ and $M$ ). Each stimulus plate is composed of four pictures. Subjects are required to point to pictures of words said by the examiner. This test takes approximately fifteen minutes to administer.

$\underline{\text { TELD }}$

The TELD is a 38 item test of receptive and expressive language with norms covering the ages of 2-5 through 7-11 years. Subjects are required to respond verbally and non-verbally (by pointing or demonstrating an action) to verbal stimuli. The test takes approximately fifteen minutes to administer.

\section{Procedures}

The group of 54 subjects was divided into three age level groups of 18 subjects. The age levels were: Group I, 3-6 to 3-9; Group II, 3-10 to 4-2; and Group III, 4-3 to 4-7. Each group consisted of 18 children ( 9 males and 9 females). Each group was further divided into three SES groups; High, Middle, and Low. There were 3 males and 3 females in each SES group. The TELD and Form $L$ of the PPVT-R were 
administered to all subjects in each group. The two tests were administered in a single session with a five minute break between tests. Counterbalancing of test ordering was accomplished by further dividing each group of 18 subjects into two groups of 9 with the tests given to these groups in the following order:

$$
\begin{aligned}
& \text { Group I: PPVT-R then TELD } \\
& \text { Group II: TELD then PPVT-R }
\end{aligned}
$$

Randomization of the sample was accomplished by numbering all permission forms consecutively as they were returned. The children were selected on the basis of how their numbers ranked on a random numbers table and on the basis of their SES level, age, and sex.

An informal hearing screen was administered to each child. Each child stood across the room (approximately eight feet) with his/her back to the examiner. Commands were delivered by the examiner at a conversational tone between 60 and $65 \mathrm{~dB}$. The examiner's voice was calibrated to insure uniform loudness level presentation of test stimuli. Each child was required to respond correctly to the following commands for their inclusion in the study: "Put your hands up," "Tell me your name," "Clap your hands," and "Sit down in the chair."

The setting for testing was a room which was isolated from other people, quiet, and well lighted. Subjects were taken from their classrooms and brought to the selected room for testing. Reinforcement for appropriate responding was delivered according to a variable ratio schedule on approximately every fourth response. The examiner reinforced with phrases such as "nice pointing" and "good listening."

The PPVT-R and the TELD were administered and scored by the 
18

investigator according to their respective manuals. The data for the analyses were age equivalents, language ages, standard scores, language quotients, and percentile ranks.

Analysis of Data

For all data analysis, the "Pearson Corr" Subprogram for the

Social Sciences was used in conjunction with a Honeywell 6640 computing system at Portland State University. Probability was measured by a two-tailed $\underline{t}$-test to determine whether or not the results were greater than chance would allow. 


\section{CHAPTER IV}

RESULTS AND DISCUSSION

The purpose of this investigation was to compare the test performances of normal preschool children on the PPVT-R to their performances on the TELD. The question posed by this study was:

What is the significance and strength of the correlation between PPVT-R age equivalents and TELD language ages?

Age equivalents and language ages appear in Appendix $C$. The PPVT-R percentiles and standard scores also were correlated with the corresponding TELD scores and mean chronological age was correlated with the PPVT-R age equivalents and with TELD language ages. The form for reporting age scores was converted from years to months for statistical analysis and interpretation.

\section{Correlations Between PPVT-R Age Equivalents} and TELD Language Ages

A Pearson Correlation was used to analyze the strength of association between the scores from the two tests and a two-tailed $\underline{t}$-test was used to analyze the level of statistical significance of each correlation. In Table I may be found correlation coefficients and $\underline{t}$-test scores, for age equivalent and language age comparisons by subject grouping. Mean age equivalents and language ages are also included according to subject grouping. 


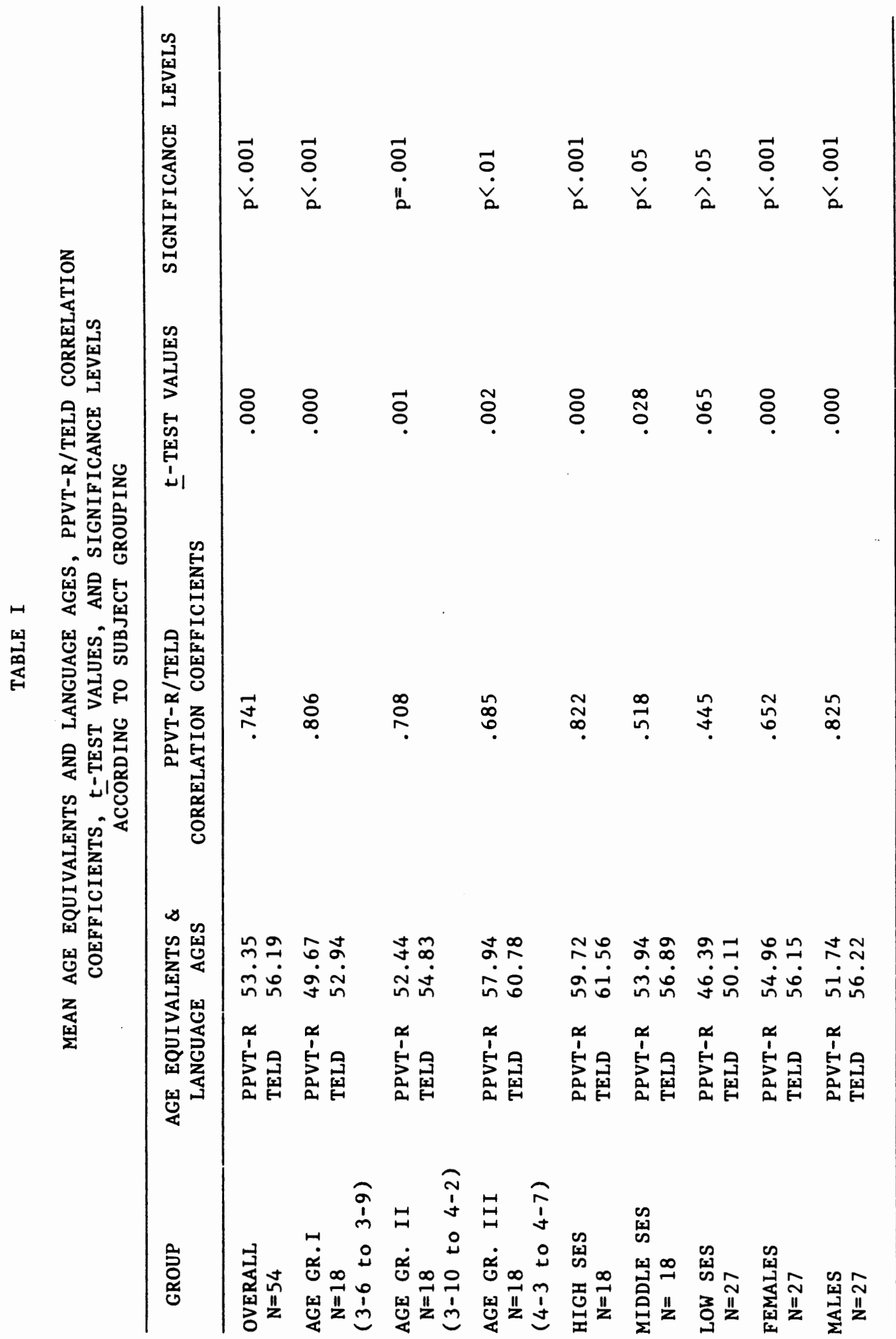


Overa11 Sample

A high correlation of .741 resulted when PPVT-R age equivalents and TELD language ages were compared. This correlation was also highly significant $\quad(p<.001)$.

Correlations between PPVT-R age equivalents and TELD language ages and analyses of significance also were made for each age group, SES group, and sex group.

Grouping by Age

The correlation between the PPVT-R age equivalents and TELD language ages for Group I (3-6 to $3-9)$ was high $(.806, p<.001)$. In Group II (3-10 to 4-2), the correlation was moderately high $(.708, \mathrm{p}=.001)$ and in Group III (4-3 to 4-7) the correlation also was moderately high $(.685, \mathrm{p}<.01)$

Grouping by SES

In the High SES Group, the comparison between age equivalents and language ages resulted in a high correlation $(.822, p<.001)$. In the Middle SES Group, the correlation was moderate $(.518, \mathrm{p}<.05)$ and in the Low SES Group, the correlation was moderate, but was not significant $(.445, \mathrm{p}>.05)$.

Grouping by Sex

In the Female Group, the comparison of age equivalents and language ages resulted in a moderate correlation $(.652, \mathrm{p}<.001)$. The correlation in the Male Group was high $(.825, \mathrm{p}<.001)$. 


\section{Correlations Between PPVT-R Standard Scores} and TELD Language Quotients

In Table II may be found correlation coefficients and $\underline{t}$-test scores for standard score and language quotient comparisons as well as standard score and language quotient means according to subject grouping.

Overall Sample

PPVT- $R$ standard scores and language quotients were compared for the entire sample and a moderately high correlation resulted (.708, $\mathrm{p}<.001)$

Grouping by Age

In Age Group I, a high correlation resulted $(.786, \mathrm{p}<.001)$. In Age Group II, the correlation was high (.744, $p<.001)$, and in Age Group III, the correlation was moderately high $(.670, \mathrm{p}<.01)$.

Grouping by SES

In the High SES Group, the comparison resulted in a high corre1ation (.715, $\mathrm{p}=.001)$. The correlation in the Middle SES Group also was high $(.716, p=.001)$ and the correlation in the Low SES Group was moderate $(.476, \mathrm{p}<.05)$.

Grouping by SEX

The comparison in the Female Group resulted in a high correlation $(.743, \mathrm{p}<.001)$ and the correlation for the Male Group also was high $(.760, \mathrm{p}<.001)$.

\section{Correlations Between PPVT-R and TELD Percentiles}

In Table III may be found correlation coefficients and $\underline{t}$-test 


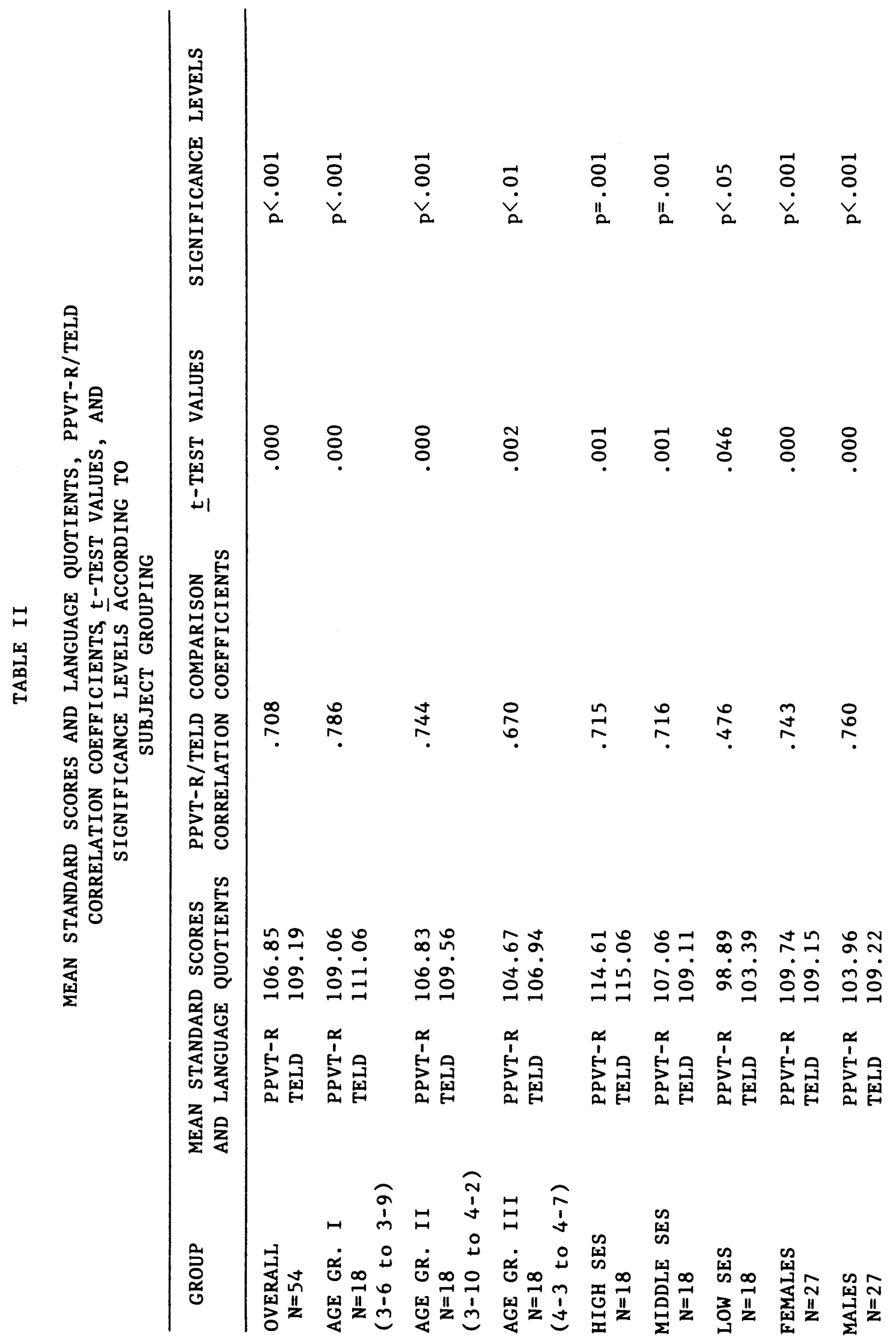




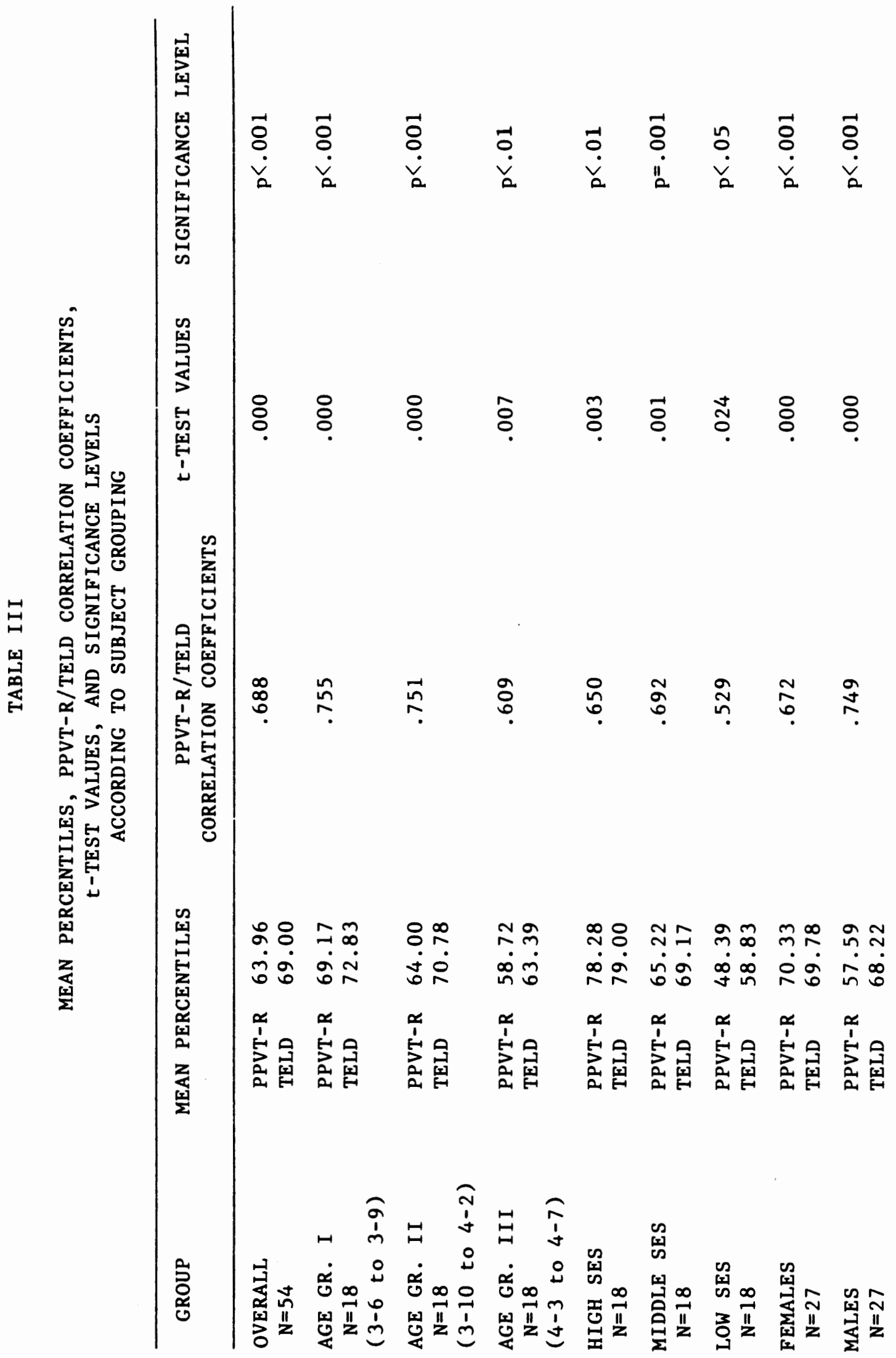


scores for percentile comparisons by subject grouping. Percentile means also are included in the Table III.

\section{Overa11 Sample}

The comparison between TELD and PPVT-R percentiles for the entire sample resulted in a moderately high correlation (.688, p<.001).

Grouping by Age

In Age Group I, the correlation which resulted when percentiles were compared was high $(.755, \mathrm{p}<.001)$. In Age Group II, the correlation was high $(.751, p<.001)$ and in Age Group III, the correlation was moderate $(.609, \mathrm{p}<.01)$.

Grouping by SES

The two percentiles were compared in the High SES Group and a moderately high correlation resulted $(.650, \mathrm{p}<.01)$. In the Middle SES Group, percentile comparison resulted in a moderately high correlation $(.692, \mathrm{p}=.001)$ and in the Low SES Group, a moderate correlation resulted $(.529, \mathrm{p}<.05)$.

Grouping by Sex

Comparison of percentiles in the Female Group resulted in a moderately high correlation $(.672, p<.001)$. Percentile comparison in the Male Group resulted in a high correlation $(.749, \mathrm{p}<.001)$.

Correlations Between Chronological Age, PPVT-R Age Equivalents, and TELD Language Ages

In Table IV, maybe found correlations and $t$-test scores for comparisons between PPVT-R age equivalents and chronological age, and correlations and $\underline{t}$-test scores for comparisons between TELD language 


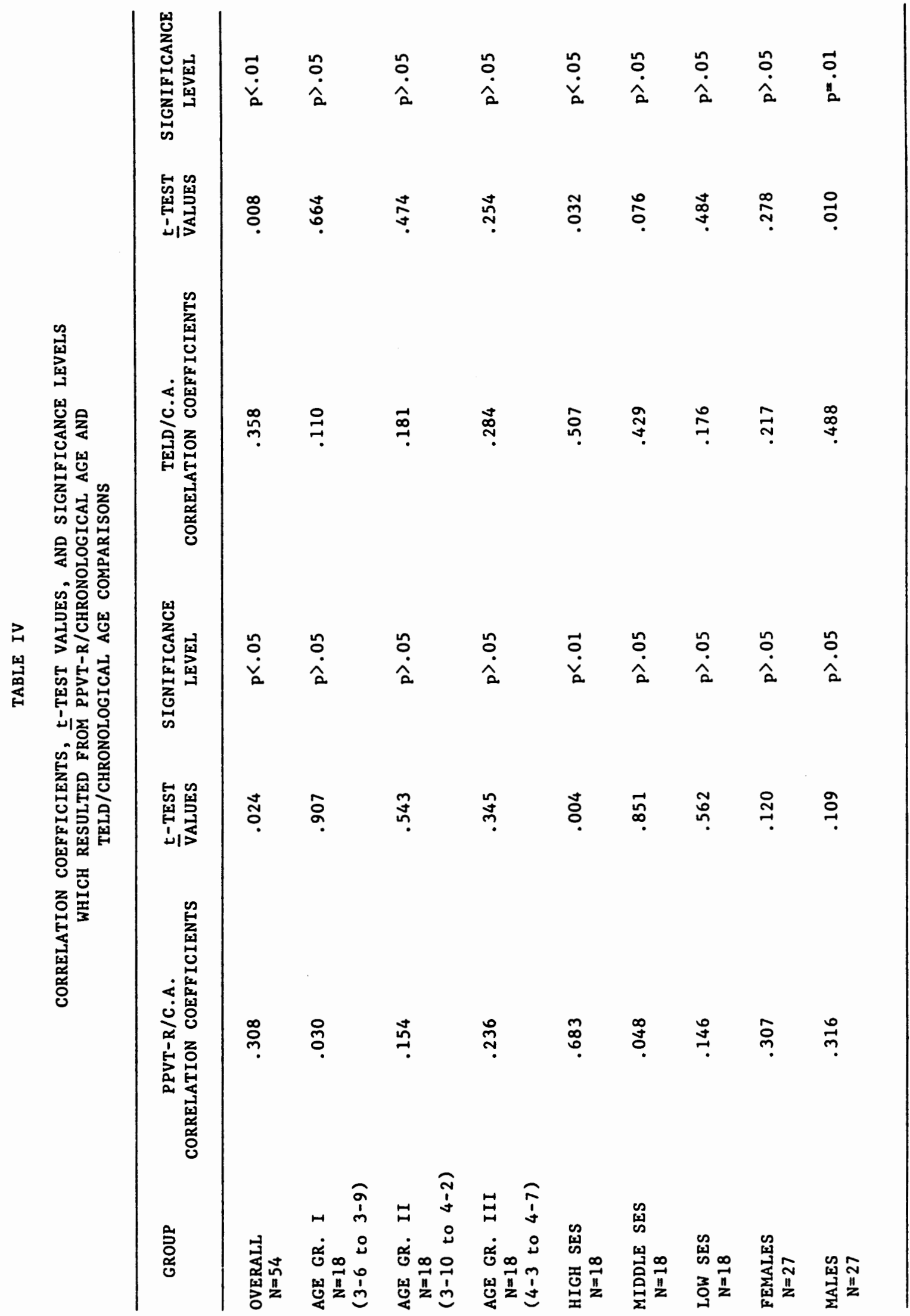


ages and chronological ages according to subject grouping.

Overal1 Sample

For the entire sample, the correlation between chronological age and PPVT-R age equivalents was low $(.308, p<.05)$. The correlation between chronological age and the TELD language ages also was low (.358, $\mathrm{p}<.01)$.

Grouping by Age

Correlations between PPVT-R age equivalents and chronological age were: Age Group I - .030, Age Group II - .154, and Age Group III .236. Correlations between TELD language ages and chronological ages were: Age Group I - .110, Age Group II - .181, and Age Group III .284. All correlations were low and were not significant $(p>05)$. Grouping by SES

Comparisons between PPVT-R age equivalents and chronological age in the High SES Group resulted in a moderately high correlation (.683, $p<.01)$. The correlation in the Middle SES Group was low (.048) and in the Low SES Group, the correlation also was low (.146). The correlations in the Middle and Low SES Groups were not beyond the .05 level of statistical significance. Comparison between TELD language ages and chronological age in the High SES Group resulted in a moderate correlation (.507, $p<.05)$. In the Middle SES Group, the correlation was moderate (.429) and in the Low SES Group the correlation was low (.176). The correlations in the Middle and Low SES Groups were not beyond the .05 level of statistical significance.

Grouping by Sex

Comparisons between PPVT- $R$ age equivalents and chronological ages for females and males were low (.307 and .316 respectively). Neither 
of the correlations was beyond the .05 level of statistical significance. Comparisons between TELD language ages and chronological ages for females resulted in a low correlation of .217 which was not beyond the .05 level of statistical significance. The comparison for males resulted in a moderate correlation $(.488, \mathrm{p}=.01)$.

\section{Differences Between PPVT-R Age Equivalents} and TELD Language Ages

In Table $V$ may be found differences between PPVT-R and TELD mean scores for the overall sample and by subject grouping.

For the entire sample, the TELD mean language age was 2.83 months higher than the mean PPVT-R age equivalent. In Age Group I, II, and II the differences were $3.28,2.39$, and 2.83 months respectively in favor of the TELD. In the High, Middle, and Low SES Groups, the differences were $1.83,2.94$, and 3.73 respectively in favor of the TELD. In the Female Group the difference was 1.18 months and in the Male Group the difference was 4.48 months in favor of the TELD.

\section{Discussion}

This investigation sought to answer the following question: What is the significance and strength of correlation between the age equivalent values of the PPVT-R and the language ages of the TELD?

The results indicated a highly significant correlation of .741 for the entire sample. This correlation is higher than correlations between the PPVT and tests of overall language ability $(.06-.53$; Carr, Brown, and Rice, 1967; Cartwright and Lass, 1974; Taylor, 1975; Sommers, Erdige, and Peterson, 1978; and Taylor, 1979). It also is 
TABLE V

NUMBER OF MONTHS BY WHICH MEAN TELD LANGUAGE

AGES ARE GREATER THAN MEAN PPVT-R AGE

EQUIVALENTS BY SUBJECT GROUPING

\begin{tabular}{|c|c|}
\hline GROUP & MEAN DIFFERENCE IN MONTHS \\
\hline $\begin{array}{c}\text { OVERALL } \\
\mathrm{N}=54\end{array}$ & 2.83 \\
\hline $\begin{array}{l}\text { AGE GR. I } \\
N=18 \\
(3-6 \text { to } 3-9)\end{array}$ & 3.28 \\
\hline $\begin{array}{l}\text { AGE GR. II } \\
N=18 \\
(3-10 \text { to } 4-2)\end{array}$ & 2.39 \\
\hline $\begin{array}{l}\text { AGE GR. III } \\
N=18 \\
(4-3 \text { to } 4-7)\end{array}$ & 2.83 \\
\hline $\begin{array}{l}\text { HIGH SES } \\
\mathrm{N}=18\end{array}$ & 1.83 \\
\hline $\begin{array}{l}\text { MIDDLE SES } \\
\mathrm{N}=18\end{array}$ & 2.94 \\
\hline $\begin{array}{c}\text { LOW SES } \\
N=18\end{array}$ & 3.73 \\
\hline $\begin{array}{c}\text { FEMALES } \\
\mathrm{N}=27\end{array}$ & 1.18 \\
\hline $\begin{array}{r}\text { MALES } \\
N=27\end{array}$ & 4.48 \\
\hline
\end{tabular}


higher than previous PPVT correlations with receptive language measures (.06 - .74; Cartwright and Lass, 1974; and Sommers, Erdige, and Peterson, 1978). It must be taken into consideration, however, that age equivalents were compared for the .741 correlation in the present study rather than standard scores as was often the case in previous studies.

When the data were analyzed within each age group, age equivalents and language ages for Age Group I (3-6 to 3-9) were the most highly correlated. As age level increased, the strength of correlations and significance decreased. These data suggest that the PPVT-R was a better predictor of language age for the youngest age group in the study than for the other two age groups. This result is in disagreement with the results from Gullo and McLoughlin's (1982) study in which standard scores were compared and the PPVT-R significantly underestimated scores on the McCarthy Scales of Children's Abilities - MSCA (McCarthy, 1972) in 3 year olds.

When the data were analyzed within SES groups, the correlation between the PPVT-R age equivalents and TELD language ages for the High SES Group was large and significant (.822). The correlation for the Middle SES Group was moderate and significant (.518) and the correlation for the Low SES Group was low and not significant (.455). Results suggest that the PPVT-R is more valid in middle to high SES children as a quick indicator of overall language ability. It should be noted that the Low SES Group included the highest percentage of Blacks compared to the other SES groups. Black children have been shown by McCallum and Bracken (1981) to score significantly lower on Form L than on Form $M$ of the PPVT-R. This factor may account for the low correlation 
between PPVT-R and TELD scores in this group. If Form $M$ had been used, the correlations may have been higher. The lower scores of Black children in this group may also be due to the differences in Black English which are not usually taken into consideration in standardized tests. The correlation between the TELD language ages and the PPVT-R age equivalents for females was moderately high and for males was high. According to these correlations, the PPVT-R appeared to be an equally good indicator of language age for both males and females in this study. In the Female Group, however, the PPVT-R mean age equivalent and the TELD mean language age were closer than the two means in the male group. This result may be due to decreased variability in the female scores (TELD range: 2-9 to 6-6 years and PPVT-R range: $3-8$ to $6-4$ years) as compared with the range of scores in the male group (TELD range: 3-6 to 6-8 years and PPVT-R range: $3-0$ to 7-7 years). Even though the correlations between the two measures were higher for males, the closeness of the scores for the Female Group combined with the moderately high correlation suggests that the PPVT-R may be slightly more valid as a language screening instrument with females.

The PPVT- $R$ mean age equivalent in the Male Group was approximately 3.22 months lower than the PPVT-R mean age equivalent for the Female Group. On the TELD, the difference between the mean language ages was .07 months in favor of the Male Group. Therefore, it appears that the age equivalents in the Male Group were slightly depressed on the PPVT-R. When administering the PPVT-R, we need to consider that males may have depressed scores as compared with females in the preschool population. The results also might suggest that females may be 
more advanced in vocabulary development in the population studied.

In all of the groups (including the group as a whole), the TELD mean language ages were higher than the PPVT-R mean age equivalents. Fraser, Bellugi, and Brown's (1963) research revealed that comprehension generally precedes production in the language development process. The results in this study are not in agreement with the hypothesis that comprehension precedes production. The disagreement may be due to the inclusion of receptive and expressive language items on the TELD rather than exclusively expressive items. The receptive items on the TELD may not be as difficult as items on the PPVT-R; hence, this may account for the higher mean language ages on the TELD as compared with mean PPVT-R age equivalents.

In all of the groups, the PPVT-R mean age equivalents were closer than the mean language ages of the TELD to the mean chronological ages of the groups; however, there was wider variation within each subject's PPVT- $R$ age equivalent and chronological age comparisons than in each subject's TELD language age and chronological age comparison. The range of scores on the PPVT-R was 3-0 to 7-7 and the TELD range was 2-9 to 6-8. Therefore, when age equivalents and language ages in each of the groups were compared with chronological age, the TELD and chronological age comparison yielded higher correlation coefficients than the PPVT-R and chronological age comparisons due to the decreased variability in TELD scores. The only significant correlations were in comparisons of TELD language ages and chronological age and PPVT-R age equivalents and chronologiccal age in the overall sample, the High SES Group, and in the Male Group. For the overall sample, the correlation 
between the TELD and chronological age was slightly higher (.358) than the PPVT-R and chronological age correlation (.308). In the High SES Group, the correlation between PPVT- $R$ age equivalents and chronological age was moderate $(.683)$ and the correlation between TELD and chronological age was moderate (.507). In the Male Group, the correlation between the TELD and chronological age was moderate, $(.488)$. The PPVT-R and chronological age correlation was not significant. Research indicates that the TELD age equivalents correlate highly (.80) with chronological age. The results of this study are not in agreement with the research and the discrepancy may be due to the broader age range studied in the TELD research.

In Choong and McMahon's (1983) study, Form L of the PPVT-R was found to yield age equivalents which were closer than those on Form $M$ to the chronological ages of 80 subjects between the ages of 3-6 and 4-6 years. If Form $M$ had been used in this study, the age equivalents may have been higher and the differences between age equivalents and language ages less. In addition, Choong and McMahon (1983) found mean PPVT- $R$ age equivalents to be 1 month higher than mean chronological age for the entire sample. The mean age equivalent of the PPVT-R in this study was approximately 5 months higher than mean chronological age for the entire sample. This difference could be due to the smaller sample or different population included in this study; however, both studies included preschool children from low, middle, and high SES levels. Since this study began, McLoughlin and Gullo (1984) reported on a similar study in which they compared 25 non-referred, middle class preschool children's (age range: $3-3$ to 5-0) standard scores on the 
PPVT-R with language quotients obtained on the TELD and the Preschool Language Scale - PLS (Zimmerman, Steiner, and Evatt, 1979). Their results indicated a moderate correlation of $.627(p<.001)$ when the standard scores from the PPVT-R and language quotients from the TELD were compared. A high correlation of $.727(p<.001)$ resulted when the PPVT-R standard scores and PLS language quotients were compared. A moderate correlation of $.519(\mathrm{p}<.01)$ resulted when the TELD and PLS language quotients were compared for the group as a whole, in this study, a correlation of $.708(p<.001)$ resulted. The higher correlation coefficient from the present study may be due to the narrower age range and the larger population included in this study. The administration of both tests in a single session in this study as opposed to administration of each test in a separate session may have affected the correlation coefficients. When the correlation between the PPVT-R standard scores and TELD language quotients from the Middle SES Group in the present study was compared with the correlation between PPVT-R standard scores and TELD language quotients in McLoughlin and Gullo's (1984) study, the correlation from the present study was higher $(.716, p<.001)$ than the McLoughlin and Gullo correlation $(.627, p<.001)$.

The mean PPVT-R standard scores and mean TELD language quotients for males and females in the McLoughlin and Gullo (1984) study were in disagreement with the differences in the present study. In the McLoughlin and Gullo study, females scored higher on the TELD and males scored higher on the PPVT-R. In the present study, the males scored higher on the TELD and females scored higher on the PPVT-R. McLoughlin and Gullo's mean PPVT-R standard score for males was 2 scaled score 
points above the mean TELD language quotient. In the present study, there was a 5.26 mean scaled score point difference which favored the TELD for the male group. McLoughlin and Gullo's female group mean for PPVT-R standard score was 8 points below the mean TELD language quotient for that group. In the present study, the difference between these two scores was .59 scaled score points in favor of the PPVT- $R$ for the female group. These results also may be due to the broader SES levels and larger population included in the present study.

When PPVT-R standard scores and TELD language quotients were compared for each group in this study, the range between correlations was smaller $(.476-.786)$ than the range between correlations obtained from the comparison of language ages and age equivalents $(.455-.825)$. All of the correlations between standard scores and language quotients were significant. Seven of the nine correlations were beyond the .001 level of statistical significance. When percentile scores from each of the two tests were compared, the range of correlations was smaller than the range for the standard scores $(.529-.755)$. All correlations were significant and six were beyond the .001 level of statistical significance. The data suggest that comparing percentiles and standard scores may be a more reliable way to compare performance of one child on two different measures.

False positive scores result when test scores indicate a language delay or disorder when the child is actually within normal limits for language development. False negatives occur when test scores indicate that a child's language development is within normal limits when it is actually delayed or disordered. In the present investigation, there 
were two possible false negative TELD scores. The PPVT-R age equivalents were between 18 and 20 months below their corresponding TELD language ages and PPVT-R standard scores were below the average range in the false negative situations. The PPVT-R indicated a delay in language development when the TELD indicated normal language development. One false negative PPVT-R score was noted in this study as compared with TELD scores. The PPVT-R age equivalent was 15 months higher than the TELD language age. The remainder of the subjects scored within normal limits for language development on both measures. Without indepth language testing of the 3 subjects, no positive conclusions can be drawn; however, these findings may support the validity of the PPVT-R as a rapid indicator of general language ability.

During testing, this investigator noted that the subjects were most willing to participate in the administration of the PPVT-R. The subjects appeared more willing to point to pictures named than to participate in the tasks required by the TELD. More instruction also was necessary with the TELD which made TELD administration and scoring a lengthier process. The TELD appeared to be rather lengthy for a quick screening device.

In summary, results of this study suggest that the PPVT-R is a conservative screening instrument as compared with the TELD. The low number of false negative PPVT-R scores, closeness of age equivalent scores to chronological ages of the normal preschool children studied, ease of administration, and high acceptability indicate that the PPVT-R may be the instrument of choice when it is necessary to screen large populations of preschool children. 


\section{CHAPTER V}

SUMMARY AND IMPLICATIONS

$\underline{\text { Summary }}$

The Peabody Picture Vocabulary Test - Revised - PPVT-R (Dunn and Dunn, 1981) is a test of hearing vocabulary which was published in 1981 It was suggested by Dunn and Dunn (1981) that the test should be useful "as an initial screening device in scanning for bright, low ability, and language impaired children who may need special attention." Since accuracy in screening is desired, information regarding the strength of the correlation between the PPVT-R and age equivalents from a comprehensive language measure was needed.

The purpose of this study was to compare PPVT-R age equivalents with language ages from the Test of Early Language Development - TELD (Hresko, Reid, and Hammill, 1981) for a preschool population. This study sought to find the strength of association between the PPVT- $R$ age equivalents and the TELD language ages. The subjects used in the study were 54 preschool children ranging in age from 3-6 through 4-7 years. Normal children were selected for the study based on their chronological age, sex, and socioeconomic status - SES.

Results indicated a significant and high correlation between the PPVT-R and TELD age equivalents and language ages, standard scores and language quotients, and also between percentiles. Results also showed that the mean TELD language age was consistently higher than 
the mean PPVT-R age equivalent for the overall sample and for each age, sex, and SES group.

The mean PPVT-R age equivalents were consistently closer than the TELD mean language ages to chronological age. The PPVT-R appeared to be slightly more valid in measuring overall language performance (as defined by the TELD) with females than with males. When results from this study were compared with the results from a similar study (McLoughIin and Gullo, 1984), the correlation coefficient from the present study was found to be higher than the coefficient from the McLoughlin and Gullo study when standard scores and language quotients from the TELD and PPVT-R were correlated. (McLoughlin and Gullo study - .627, p>.001; present study $-.708, p>.001)$.

\section{Implications}

\section{Clinical Implications}

From this study, the PPVT-R appears to be a conservative measure of language development for preschool children (as defined by the TELD). It should be taken into consideration, however, that the PPVT-R appears especially useful when working within a limited time period. Obviously the PPVT-R should not be used as the sole evaluation instrument, but the closeness of age equivalent scores to chronological ages of normal children, ease of administration, high acceptibility, and high correlation with TELD language ages, language quotients, and percentiles in this study and in McLoughlin and Gullo's (1984) study, support the use of the PPVT-R in screening. Disagreements in the test scores of males and females and SES groups need to be taken into consideration when 
interpreting test scores, but this disagreement does not appear to indicate that the PPVT-R should not be used in preschool screening.

\section{Research Implications}

A replication study with a language disordered or delayed population would yield results which would aid in determining the PPVT-R's validity in screening for language disordered and delayed children.

Studies with subjects from different age groups than the age groups used in this study would be helpful in determining possible limitations of the PPVT-R as a screening instrument with various age groups.

Further examination of the data in this study is indicated in order to determine why mean TELD language scores always were higher than mean PPVT-R scores. This may be done by comparing, separately, expressive and receptive items passed on the TELD to the number of passed items on the PPVT-R.

A comparison of the PPVT-R with more extensive language measures with the same population would yield further information as to the validity of the PPVT-R as an overall language screening instrument.

The significant differences between mean TELD and PPVT-R scores, and the differences between the TELD language ages and chronological ages, lead this researcher to question the validity of the TELD as a quick screening measure for detecting language delays and language disorders in preschool children. It is suggested that the TELD be compared to other, extensively researched language measures to determine whether language ages obtained by preschool children on the TELD are inflated when compared with other language measures for preschool children. 


\section{BIBLIOGRAPHY}

AMMONS, B. \& AMMONS, H. (1948). The Full Range Picture Vocabulary Test. Missoula: Psychological Test Specialists.

BREEN, M.M. (1981). Comparison of the Weschsler Intelligence Scale for Children-Revised and the Peabody Ficture Vocabulary Test-Revised for a referral population. Psychological Reports, 49, 717-718.

CARR, D.L., BROWN, L.F., \& RICE, J.A. (1967). The PPVT in the assessment of language deficits. American Journal of Mental Deficiency, 6 , 937-939.

CARROW, E. (1973). Test for Auditory Comprehension of Language. Austin: Learning Concepts.

CARTWRIGHT, L.H. \& LASS, N.J. (1974). A comparative study of children's performances on the Token Test, Northwestern Syntax Screening Test, and the Peabody Picture Vocabulary Test, Acta Symbolica, 5, $19-29$.

CHOONG, J. \& MCMAHON, J. (1983). Comparison of scores obtained on the PPVT and the PPVT-R. Journal of Speech and Hearing Disorders, $48,40-43$.

COVIN, T.M. (1977). Relationship of the SIT and PPVT to the WISC-R. Journal of School Psychology, 15, 259-260.

DARLEY, F.L. \& SPRIESTERSBACH, D.C. (1978). Diagnostic methods in speech pathology. New York: Harper and Row.

DERENZI, E. \& VIGNOLO, L. (1968). The Token Test: A sensitive test to detect receptive disturbances in aphasics. Brain, 85, 655678 .

DILORENZO, L.T. \& BRADY, J.J. (1968). Use of the Peabody Picture Vocabulary Test with preschool children. Psychological Reports, 247-251.

DUNN, L.M. (1959). Peabody Picture Vocabulary Test. Circle Pines: American Guidance Service.

DUNN, L.M. \& DUNN, L. (1981). Peabody Picture Vocabulary Test-Revised. Circle Pines: American Guidance Service.

DUNN, L.M. \& MARKQWARDT, F.C. (1970). Peabody Individual Achievement Test. Circle Pines: American Guidance Service. 
EMERICK, L.L. \& HATTEN, J.T. (1979). Diagnosis and evaluation in speech pathology. Englewood Cliffs: Prentice-Hall.

FRASER, C. , BELLUGI, U. \& BROWN, R. (1963). Control of grammar in imitation comprehension, and production. Journal of Verbal Learning and Verbal Behavior, 3, 121-135.

GULlO, D.F. \& MCLOUGHLiN, C.S. (1982). Comparison of scores for normal children on Peabody Picture Vocabulary Test-Revised and McCarthy Scales of Children's Abilities Psychological Reports, $51,623-626$.

HRESKO, W.P., REID, D.K. \& HAMMILL, D.D. (1981). Test of Early Language Development. Austin: Pro-Ed.

JOINER, L.M. (1978). Identifying children with special needs. Holmes Beach: Learning Publications, Inc.

KIRK, S.A., MCCARTHY, J.J.\& KIRK, W.D. (1968). Illinois Test of Psycholinguistic Abilities. Urbana: The University of Illinois Press.

LEE, L. (1971). Northwestern Syntax Screening Test. Evanston: Northwestern University Press.

MCCALLUM, R.S. \& BRACKEN, B. (1981). Alternate form reliability of the PPVT-R for white and black preschool children. Psychology in the Schools, $18,422-425$.

MCCARTHY, D. (1972). McCarthy Scales of Children's Abilities. New York: The Psychological Corporation.

MCLOUGHLIN, C.S. \& GULLO, D.F. (1984). Comparison of three formal methods of preschool language assessment. Language, Speech, and Hearing Services in Schools, 15 (3), 146-153.

NAGLIERI, J.A. (1981). Concurrent validity of the Revised Peabody Picture Vocabulary Test. Psychology in the Schools, 18, 286-289.

NAGLIERI, J.A. \& NAGLIERI, D.A. (1981). Comparison of the PPVT and PPVT-R for preschool children - Implications for the practitioner. Psychology in the Schools, 18, 434-436.

NEWCOMER, P. \& HAMMILL, D. (1977). The Test of Language Development, Austin: Pro-Ed.

PEDRIANA, A.J. \& BRACKEN, B.A. (1982). Performance of gifted children on the PPVT and PPVT-R. Psychology in the Schools, 19, 183-185.

PIERS, E.V. (1965). Review of the PPVT. Sixth mental measurements yearbook. 0.K. Buros (ed.), Highland Park: The Gryphon Press, 531-532. 
PRASSE, D.F. \& BRACKEN, B.A. (1981). Comparison of the PPVT-R and WISC-R with urban educable mentally retarded students. Psychology in the Schools, 18, 174-177.

RITTER, D.R., DUFFEY, J.E. \& FISCHMAN, R. (1974). Comparison of the intellectual estimates of the Draw-A-Person Test, Peabody Picture Vocabulary Test, and Stanford-Binet ( $L-M$ ) for kindergarten children. Psychology in the Schools, 11, 412-415.

SOMMERS, R.K., ERIDGE, S.\& PETERSON, M.K. (1978). How valid are children's language tests. The Journal of Special Education, $12,393-407$.

STONER, S.B. (1981). Alternate form reliabilitiy of the revised PPVT for head start children. Psychological Reports, 49, 628.

TAYLOR, L.J. (1975). The Peabody Picture Vocabulary Test: What does it measure? Perceptual and Motor Ski11s, 41, 777-778.

TAYLOR, R.L. (1979). Comparison of the McCarthy Scales of Children's Abilities and the Peabody Picture Vocabulary Test. Psychological Reports, 45, 196-198.

TERMAN, L. \& MERRILL, M. (1960). Stanford-Binet Intelligence Scales, Boston: Houghton-Mifflin.

U.S. BUREAU OF THE CENSUS (1963). Methodology and scores of socioeconomic status. Working Paper No. 15, Washington, D.C.

U.S. BUREAU OF THE CENSUS (1979). Statistical abstract of the United States: Washington, D.C.

WECHSLER, D. (1974). Wechsler Intelligence Scale for Children-Revised. New York: The Psychological Corporation.

ZIMMERMAN, I.L., STEINER, V.G. \& EVATT, R.L. (1979). Preschool Language Scale. Columbus: Charles E. Merrill. 


\title{
APPENDIX A
}

\author{
PERMISSION FORM
}

I agree to let my child , (Birthdate $\overline{M o}^{\prime} \overline{\mathrm{Da}}$ ' $\overline{\mathrm{Yr}}$

as a subject in a study entitled "Comparison of Scores Obtained on the Peabody Picture Vocabulary Test-Revised (PPVT-R) and the Test of Early Language Development (TELD)." These are both frequently used tests of children's language development. Children with normal language skills are needed for this study being carried out by Ms. Diana Schneider under the supervision of Professor Joan McMahon, Thesis Director, Speech and Hearing Sciences Program, Portland State University.

I understand the purpose of this study is to find out if there is a positive correlation between the test scores. My child will be tested on one occasion. The session will last about 30 minutes. All children will, be identified only by number, no names will be used at any time, and all information on this form will be kept confidential.

There are no risks or dangers inherent in the procedures of the study. If any child is anxious about the testing situation, he/she will be assured that he/she has nothing to be anxious about. If the anxious behavior persists, the child will be taken back to his/her classroom without jeopardizing his/her position in the preschool. My child will simply be asked to point to pictures, repeat phrases, and answer questions.

Please return this form tomorrow indicating your permission with your child. If you have any questions, you can leave a message with the preschool director and Diana Schneider will return your call.

The following information is needed for data analysis:

Years of Education of Major Wage Earner of Your Family

Occupation of Major Wage Earner of Your Family

Signature of Parent/Guardian 


\section{APPENDIX B}

\section{SPECIFICATIONS}

\section{General Radio Sound Level Meter - ANSI II}

C-weighted scale, examiner's voice between 60 and $65 \mathrm{~dB}$ at $8 \mathrm{ft}$. for $3 / 5$ trials.

A-weighted scale, examiner's voice between 55 and $60 \mathrm{~dB}$ at $8 \mathrm{ft}$. for $3 / 5$ trials.

This sound level meter is a survey meter to roughly determine acoustic events in a surrounding environment. It was used in this study as an aid in monitoring the average intensity level of spoken stimuli by the examiner.

\section{Electro-Voice RE 15 Dynamic Cardoid M Microphone}

Element: Dynamic

Frequency response: $80-13,000 \mathrm{~Hz}$

Polar Pattern: Omnidirectional

Impedance: Low (150 ohms)

Output level: $-55 \mathrm{~dB}\left(0 \mathrm{~dB}=1 \mathrm{mw} / 10\right.$ dynes $\left./ \mathrm{cm}^{2}\right)$

EIA sensitivity rating: $-149 \mathrm{~dB}$

Berlant Concertone Series 30 model 2203 Mixer with VU Meter

(Marion Electric Instrument Co.)

This was used to monitor and condition the intensity of the examiner's delivery of stimuli. 
APPENDIX C

AGE EQUIVALENTS AND LANGUAGE AGES

\begin{tabular}{|c|c|c|c|c|c|}
\hline Subject & C.A. & $\underline{\text { Sex }}$ & SES & PPVT-R & TELD \\
\hline 1 & $3-7$ & $\mathbf{M}$ & High & $4-10$ & 4-11 \\
\hline 2 & $3-9$ & $\mathbf{M}$ & $\mathrm{High}$ & $3-8$ & $4-1$ \\
\hline 3 & $3-6$ & $M$ & $\mathrm{High}$ & $3-10$ & 4-1 \\
\hline 4 & $3-6$ & $F$ & $\mathrm{High}$ & $5-4$ & $6-6$ \\
\hline 5 & $3-9$ & F & $\mathrm{High}$ & $3-11$ & $3-10$ \\
\hline 6 & $3-8$ & $F$ & High & $4-0$ & $4-3$ \\
\hline 7 & $3-9$ & $\mathbf{M}$ & Middle & $4-2$ & $5-0$ \\
\hline 8 & $3-8$ & $\mathbf{M}$ & Middle & $4-2$ & $3-10$ \\
\hline 9 & $3-6$ & $\mathbf{M}$ & Middle & $3-11$ & $4-0$ \\
\hline 10 & $3-9$ & $\mathbf{F}$ & Middle & $4-5$ & $4-7$ \\
\hline 11 & $3-8$ & $F$ & Middle & $5-5$ & $4-11$ \\
\hline 12 & $3-9$ & $F$ & Middle & 4-1 & $4-5$ \\
\hline 13 & $3-6$ & $M$ & Low & $3-1$ & $3-10$ \\
\hline 14 & $3-8$ & $M$ & Low & $3-3$ & $4-0$ \\
\hline 15 & $3-9$ & M & Low & $4-6$ & $4-11$ \\
\hline 16 & $3-6$ & F & Low & $4-6$ & $4-8$ \\
\hline 17 & $3-9$ & F & Low & $3-8$ & $3-9$ \\
\hline 18 & $3-6$ & F & Low & $3-9$ & $3-10$ \\
\hline 19 & $3-10$ & M & High & $4-9$ & $4-10$ \\
\hline 20 & 4-2 & $M$ & $\mathrm{High}$ & $5-3$ & $6-3$ \\
\hline 21 & $4-0$ & $\mathbf{M}$ & $\mathrm{High}$ & $5-2$ & $4-8$ \\
\hline 22 & $3-11$ & F & $\mathrm{High}$ & $4-2$ & $4-10$ \\
\hline 23 & 4-2 & F & $\mathrm{High}$ & $4-5$ & $4-10$ \\
\hline 24 & $4-1$ & F & High & $4-10$ & $4-8$ \\
\hline 25 & $3-10$ & M & Middle & $4-6$ & $4-8$ \\
\hline 26 & $3-11$ & $\mathbf{M}$ & Middle & $4-10$ & $4-8$ \\
\hline 27 & $3-11$ & $M$ & Middle & $3-3$ & $3-9$ \\
\hline 28 & 4-1 & F & Middle & $4-1$ & $5-0$ \\
\hline 29 & $3-10$ & F & Middle & $6-4$ & $5-0$ \\
\hline 30 & $4-2$ & F & Middle & $4-3$ & $5-0$ \\
\hline 31 & $4-1$ & $M$ & Low & $3-5$ & $3-10$ \\
\hline 32 & $3-10$ & $M$ & Low & $4-1$ & $4-7$ \\
\hline 33 & 4-1 & M & Low & $3-6$ & $3-6$ \\
\hline 34 & $3-10$ & F & Low & $4-5$ & $4-7$ \\
\hline 35 & $4-0$ & F & Low & $4-2$ & $4-5$ \\
\hline 36 & $3-11$ & F & Low & $4-2$ & $4-0$ \\
\hline 37 & $4-4$ & $M$ & High & $5-2$ & $5-3$ \\
\hline 38 & $4-5$ & M & $\mathrm{High}$ & $6-9$ & $6-8$ \\
\hline 39 & $4-6$ & $M$ & $\mathrm{High}$ & $7-7$ & $6-6$ \\
\hline 40 & $4-4$ & F & $\mathrm{High}$ & $5-1$ & 5-9 \\
\hline
\end{tabular}




\begin{tabular}{clllll} 
Subject & C.A. & Sex & SES & PPVT-R & TELD \\
\cline { 2 - 7 } 41 & $4-5$ & F & High & $5-7$ & $6-0$ \\
42 & $4-4$ & F & High & $5-3$ & $4-5$ \\
43 & $4-6$ & M & Middle & $3-2$ & $4-8$ \\
44 & $4-6$ & M & Middle & $4-2$ & $4-1$ \\
45 & $4-3$ & M & Middle & $5-0$ & $6-0$ \\
46 & $4-6$ & F & Middle & $4-10$ & $4-10$ \\
47 & $4-7$ & F & Middle & $5-8$ & $5-2$ \\
48 & $4-6$ & F & Middle & $4-8$ & $5-9$ \\
49 & $4-6$ & M & Low & $3-11$ & $5-2$ \\
50 & $4-4$ & M & Low & $3-0$ & $4-8$ \\
51 & $4-3$ & M & Low & $3-6$ & $4-1$ \\
52 & $4-3$ & F & Low & $4-0$ & $2-9$ \\
53 & $4-5$ & F & Low & $5-5$ & $4-10$ \\
54 & $4-5$ & $F$ & Low & $4-2$ & $4-7$
\end{tabular}




\section{APPENDIX D}

PPVT-R TEST FORM
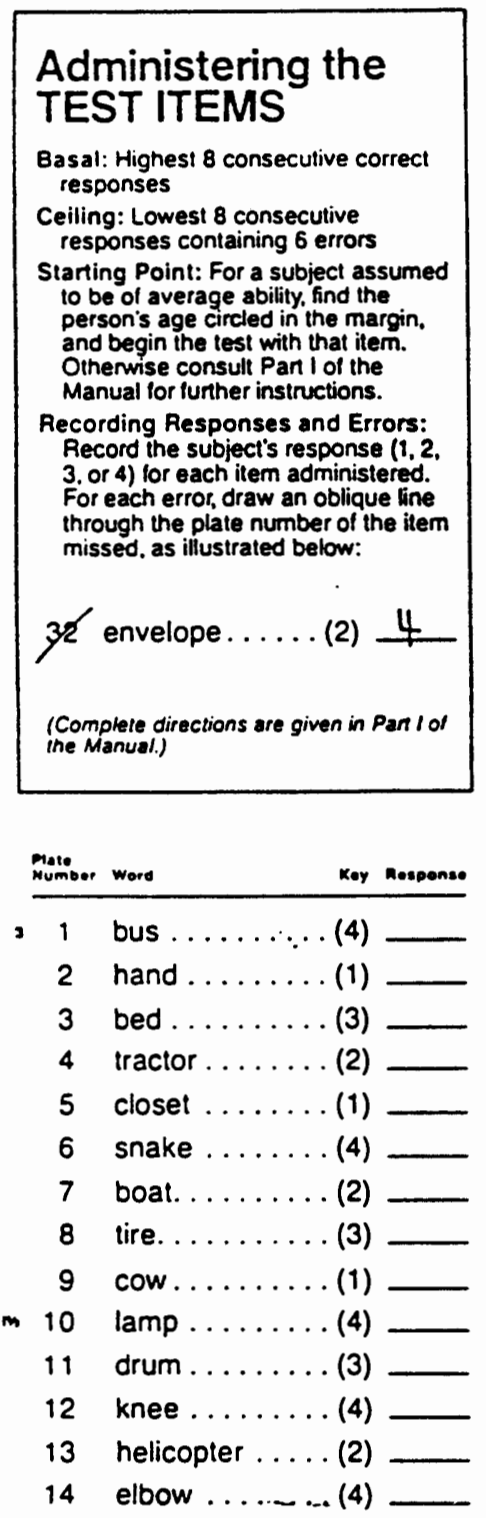

mote

Number wos

46 decorated ..... (3)

47 trame ........ (1)

48 forest......... (3)

49 faucet ........ (2)

Koy คosponse

50 group ........ (3)

51 stem ......... (3)

52 vase ......... (3)

53 pedal......... (1)

54 capsule....... (2)

I

55 surprised...... (4)

(2)

56

bark.

(2)

57

mechanic

(2)

3)

1)

3)

2)

58

- 59

tambourine

(1)

disappointment . (4)

(4)

(3)

awarding ...... (3)

pitcher........ (3)

(3)

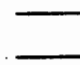

(3)

60

62

63

reel.

(1)

signal

trunk.

(2)

2)

- 65

66

human.

nostril

(1)

disagreement ... (1)

exhausted.....

vine. . . . . . . (4)

(4)

ceremony .... . (4)

casserole ..... (2)

globe. ......... (3)

filing .

clamp

reptile ....... (2)

(1)

island .

spatula

(3)

79 cooperation.... (4)
Muste

Key Mosponse

111 Iransparent.... (3)

112 husk......... (1)

113 utensil........ (2)

114 citrus......... (3)

115 pedestrian..... (2)

116 parallelogram .. (1)

117 slumbering ..... (3)

peninsula ..... (4)

119

120

upholstery..... (2)

(4)

barricade.

quartet

122

tranquil

(1)

abrasive

(3)

124

fatigued.

spherical

syringe

126

127

feline

(2)

128

arid.

(4)

129

exterior

constellation ... (4)

(4)

cornea.

(2)

mercantile ..... (1)

ascending . . . . (3)

filtration....... (1)

(4)

consuming .... (4)

(4)

cascade

perpendicular .. (3)

replenishing .... (1)

(3)

emission ...... (3)

(3)

talon.

wrath.

incandescent .. (4)

arrogant ...... (2)

(2)

(3) $\longrightarrow$

$-$

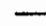

$-$

$\longrightarrow$ 


\begin{tabular}{|c|c|c|c|c|c|c|c|c|}
\hline 15 & bandage $\ldots . .$. (4) & & 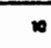 & - 80 & scalp ........ (4) & & 145 & rhombus ....... (3) \\
\hline 16 & feather ....... (1) & & & 81 & Iwig. ......... (2) & & 146 & nautical. \\
\hline 17 & empty ........ (3) & & & 82 & weasel ...... (2) & & 147 & tangent....... (1) \\
\hline 18 & fence........ (4) & & & 83 & demolishing ... (4) & & 148 & inclement ..... (4) \\
\hline 19 & accident ...... (2) & & & 84 & balcony....... (1) & & 149 & trajectory...... (1) \\
\hline * 20 & net. . . . . . (2) & & n & 85 & locket ....... (1) & & 150 & fettered....... (1) \\
\hline 21 & tearing........ (4) & & & 86 & amazed....... (3) & & 151 & waif......... (3) \\
\hline 22 & sail ........ (1) & & & 87 & tubular. ....... (1) & & 152 & jubilant ....... (2) \\
\hline 23 & measuring..... (2) & & & 88 & tusk.........(1) & & 153 & pilfering....... (4) \\
\hline 24 & peeling ....... (3) & & & 89 & bolt ......... (3) & & 154 & repose........ (2) \\
\hline 25 & cage ........ (1) & & 12 & 90 & communication . (4) & & 155 & carrion. ....... (3) \\
\hline 26 & tool ........ (4) & & & 91 & carpenter ..... (2) & & 156 & indigent. . . . . (2) \\
\hline 27 & square........ (4) & & & 92 & isolation ...... (1) & & 157 & convex ....... (1) \\
\hline 28 & stretching $\ldots .$. (1) & & & 93 & infiated ....... (3) & & 158 & emaciated..... (2) \\
\hline 29 & arrow......... (2) & & & 94 & coast. . . . . . (3) & & 159 & divergence .... (4) \\
\hline 330 & tying $\ldots \ldots \ldots$ (2) & & 13 & 95 & adjustable..... (2) & & 160 & dromedary .... (2) \\
\hline 31 & nest......... (1) & & & 96 & fragile $\ldots \ldots \ldots$ (3) & & 161 & embellishing ... (2) \\
\hline 32 & envelope...... (2) & & & 97 & assaulting ..... (1) & & 162 & entomologist... (3) \\
\hline 33 & hook........ (3) & & & 98 & appliance ..... (1) & & 163 & constrain...... (1) \\
\hline 34 & pasting ....... (4) & & & 99 & pyramid. ...... (4) & & 164 & infirm........ (1) \\
\hline * 35 & patting........ (1) & & n & 100 & blazing ...... (1) & & 165 & anthropoid. .... (3) \\
\hline 36 & penguin. ....... (1) & & & 101 & hoisting....... (1) & & 166 & specter ...... (4) \\
\hline 37 & sewing $\ldots \ldots \ldots$ (2) & & & 102 & arch........ (4) & & 167 & incertitude..... (2) \\
\hline 38 & delivering ..... (1) & & & 103 & lecturing ...... (4) & & 168 & vitreous....... (1) \\
\hline 39 & diving $\ldots \ldots \ldots$ (2) & & & 104 & dilapidated ... . (4) & & 169 & obelisk ....... (1) \\
\hline - 40 & parachute ..... (3) & & is & 105 & contemplating .. (2) & & 170 & embossed..... (4) \\
\hline 41 & furry ........ (4) & & & 106 & canister....... (1) & & 171 & ambulation .... (2) \\
\hline 42 & vegetable ..... (4) & & & 107 & dissecting ..... (3) & & 172 & calyx ......... (2) \\
\hline 43 & shoulder...... (3) & & & 108 & link ........ (4) & & 173 & osculation..... (3) \\
\hline 44 & dripping. . . . . . (2) & & & 109 & solemn ....... (3) & & 174 & cupola........ (4) \\
\hline 45 & claw ........ (4) & & w & 110 & archery... & & 175 & homunculus ... (4) \\
\hline
\end{tabular}

NOTE: Ages in circles reler to the lowest age in a 6. or 12-month intervat. For example, them 1 is the starting tiem for ages 2-6 through 3-5, and them 30 lor ages 5-0 through 5-5. Use ltem 110 for ages 16.0 and over.

\section{Calculating Raw Score}

Ceiling item.

minus errors

American Guidance Service, cin Pines, MN 55014 AGS

Raw score.

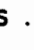




\section{TELD \\ Test of Early Language \\ Development}

Wayne P. Hresko

D. Kim Reid

Donald D. Hammill

Section III.

\section{PERFORMANCE RECORD}

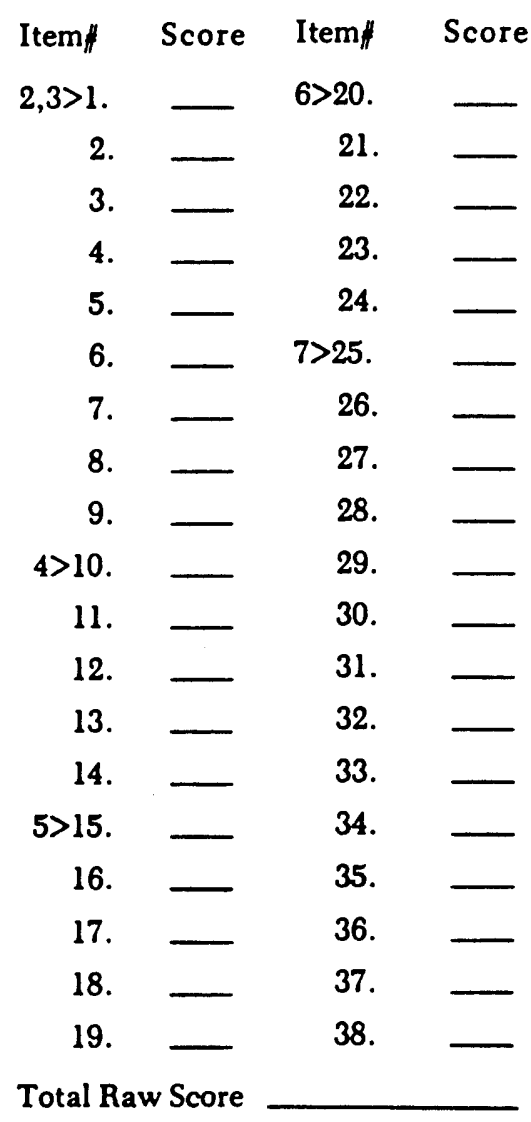

OHresko, Reid, \& Hammill 1981
Section I.

IDENTIFYING INFORMATION

Name:

Female $\square \quad$ Male $\square$

School:

Teacher's Name:

Examiner's Name:

Examiner's Title:

Referred By:

Section II. CHILD'S AGE

Yr. Mo.

Date Tested

Date of Birth

Age

Section IV. TELD RESULTS

Total Raw Score

Language Quotient

Percentile Score

Language Age

Section V. OTHER TEST RESULTS

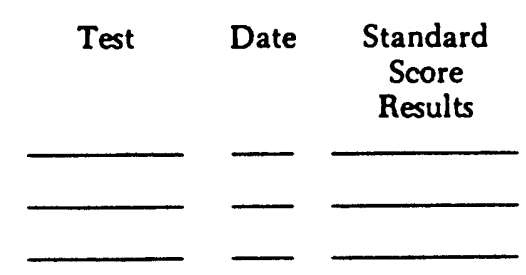

Additional copies of this form are available from PRO-ED, 5341 Industrial Oaks Blvd. Austin, Texas $\mathbf{7 8 7 3 5}$ 